\title{
eThrombosis: the 21st Century variant of venous thromboembolism associated with immobility
}

\author{
R. Beasley*, , N. Raymond ${ }^{\#}$, S. Hill ${ }^{\#}$, M. Nowitz ${ }^{\#}$, R. Hughes*
}

\begin{abstract}
eThrombosis: the 21st Century variant of venous thromboembolism associated with immobility. R. Beasley, N. Raymond, S. Hill, M. Nowitz, R. Hughes. (C) ERS Journals Ltd 2003.

ABSTRACT: The association between immobility with prolonged sitting and venous thromboembolism has been recognised for $>\mathbf{6 0} \mathrm{yrs}$, most recently with long distance air travel. The case of a 32-yr-old male, in whom immobility associated with sitting for long periods at a computer represented the major provoking risk factor for his lifethreatening venous thromboembolism, is presented. The authors propose the term "eThrombosis" to describe this 21st Century variant of venous thromboembolism associated with immobility from prolonged sitting. In view of the widespread use of computers in relation to work, recreation and personal communication, the potential burden of eThrombosis may be considerable.

Eur Respir J 2003; 21: 374-376.
\end{abstract}

The link between prolonged sitting and venous thromboembolism (VTE) was first recognised during the London blitz in World War II when Simpson [1] reported fatal pulmonary embolism occurring in persons who had sat for prolonged periods in deck chairs while taking refuge in air-raid shelters. In 1954 Homans [2] reported that VTE may occur after prolonged sitting in a number of other situations, such as in aeroplane flights, car trips and even attendance at the theatre. More recently interest has focused on VTE associated with prolonged air travel, due in part to the reported frequency of VTE in up to $10 \%$ of high-risk travellers and the trend of increasing air travel with $>1$ billion passengers flying every year $[3,4]$. Another sedentary life-style pattern that has developed over recent decades is the extensive use of computers in relation to work, recreation and personal communication. In this report the authors present a case in which immobility associated with sitting for long periods at a computer represented the major provoking risk factor for a life-threatening VTE.

\section{Case report}

The authors report the case of a 32-yr-old male who gave a history of a swollen painful calf 6 weeks previously, which resolved after 10 days. During the 4 weeks prior to presentation he noticed increasing breathlessness on exertion, to the extent that he was breathless during minimal activity. On the day of the
* Medical Research Institute of New Zealand, ${ }^{\#}$ Wellington Hospital, Capital \& Coast District Health Board, Wellington, New Zealand and "University of Southampton, Southampton, UK.

Correspondence: R. Beasley, Medical Research Institute of New Zealand, PO Box 10055, Wellington, New Zealand. Fax: 6444729224

E-mail: richard.beasley@mrinz.ac.nz

Keywords: Deep vein thrombosis, eThrombosis, immobility, pulmonary embolism, venous thromboembolism

Received: May 132002

Accepted after revision: June 262002 presentation he experienced a syncopal episode in which he lost consciousness. He denied haemoptysis or pleuritic pain; there was no family history of VTE. On examination he was afebrile, heart rate 120 beats $\cdot \mathrm{min}^{-1}$, blood pressure 130 over 95 , respiratory rate $20 \mathrm{breaths} \cdot \mathrm{min}^{-1}$, jugular venous pressure not raised, chest clear on auscultation and prominent facial contusions were noted.

The electrocardiogram showed sinus tachycardia and severe right heart strain (fig. 1); arterial blood gases on room air showed $\mathrm{pH} 7.45$, carbon dioxide arterial tension $3.86 \mathrm{kPa}(29 \mathrm{mmHg})$, arterial oxygen tension $7.45 \mathrm{kPa}(56 \mathrm{mmHg})$, bicarbonate $19 \mathrm{mmol} \cdot \mathrm{L}^{-1}$, oxygen saturation $93 \%$ and the chest radiograph showed prominence of the hila and airspace consolidation of the superior segment of the left lower lobe. A provisional diagnosis of pulmonary embolism was made and this was confirmed by pulmonary angiography with helical computer tomography angiogram, which showed extensive bilateral proximal thrombus (figs. 2 and 3). Echocardiography showed paradoxical interventricular septal movement, a dilated right ventricle, a right ventricular pressure of $25 \mathrm{mmHg}$ and no evidence of intracardiac thrombus. A decision was made not to administer thrombolysis, due to the risk of intracerebral bleeding associated with his traumatic head injury. Instead, he received short-term low molecular weight heparin and concomitant oral warfarin, which was continued for a 6-month period. Following this 6-month period he reported that he had made a full symptomatic recovery. A follow-up ventilation/ perfusion scan indicated that there had been a marked resolution of the pulmonary emboli and a thrombophilia 
VR

V1

V4

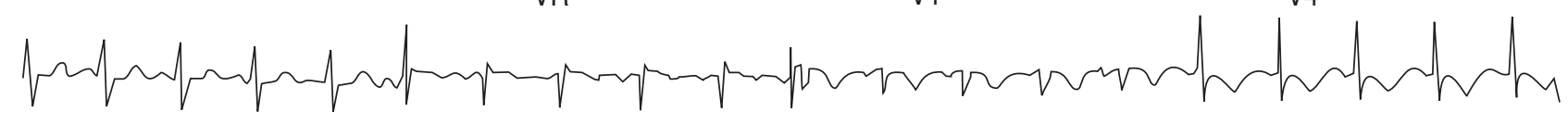

II $\quad$ aVL

V2

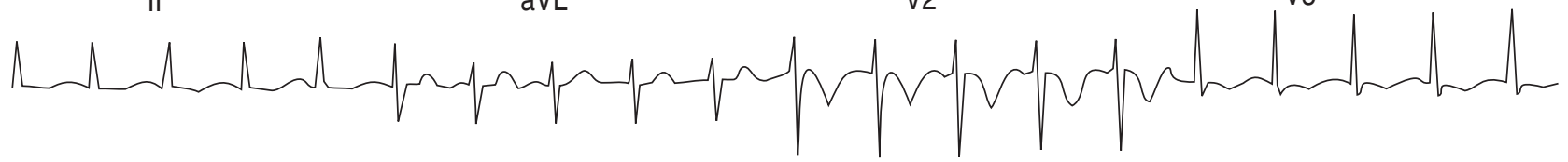

III $\quad$ aVF

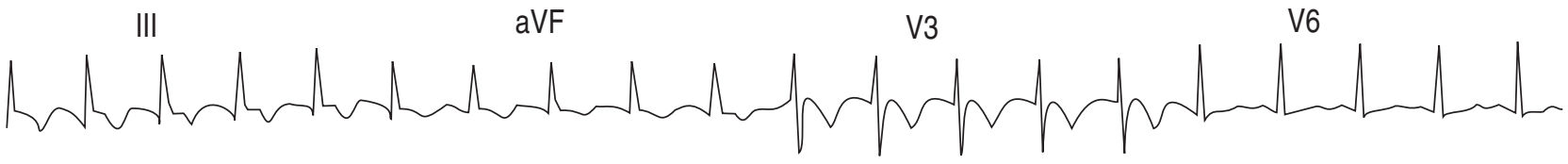

II

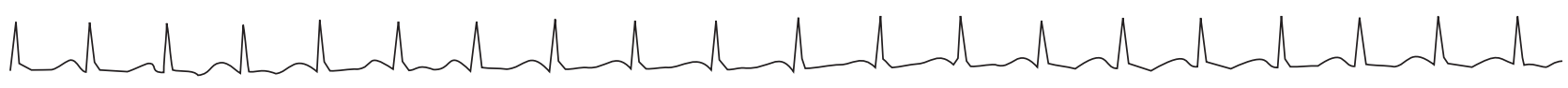

Fig. 1.-Electrocardiogram showing severe right heart strain.

screen was normal. A Doppler ultrasound examination of the lower limbs was not undertaken on the basis that it would not influence management.

In the absence of recognised risk factors for his VTE, interrogation identified immobility associated with sitting for long periods at a computer terminal both at work and at home. This regularly involved sitting at his computer for $12 \mathrm{~h}$ per day and on occasions up to $18 \mathrm{~h}$. He would typically sit for $1-2 \mathrm{~h}$, and not infrequently as many as $6 \mathrm{~h}$, without standing up from his workstation.

\section{Discussion}

To the authors' knowledge, this is the first reported case of an association between repeated prolonged

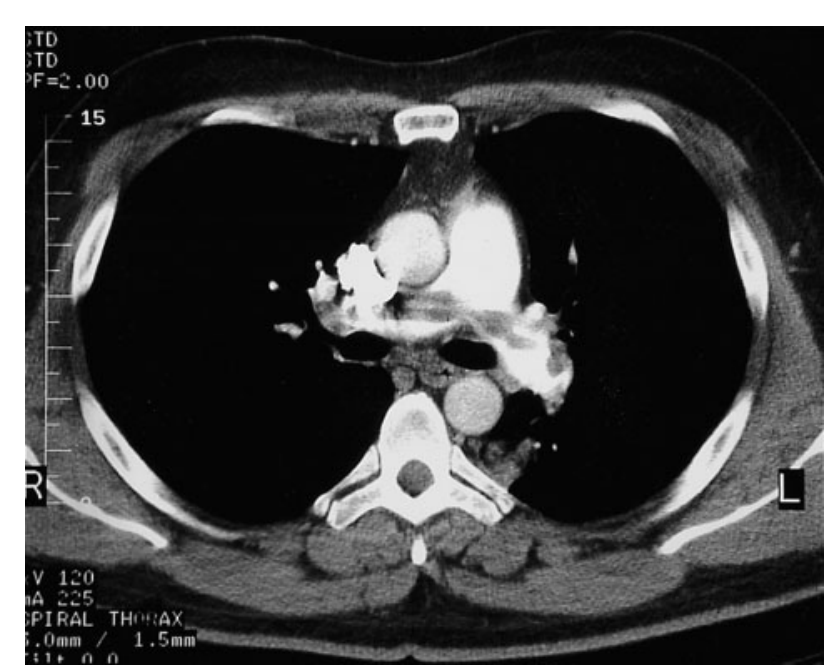

Fig. 2.-Helical computed tomography angiogram showing saddle embolus straddling the bifurcation of the pulmonary artery. immobility sitting at a computer and life-threatening VTE. The term "eThrombosis" to describe this $21 \mathrm{st}$ Century variant of thrombosis associated with immobility from prolonged sitting is proposed.

The incidence of this condition may be substantial when considering the widespread use of computers in so many aspects of modern life. For example, in the USA, one-half of all employed adults use a computer at work, just over one-half of all households have a computer and home internet use doubled in the $3 \mathrm{yrs}$ from 1997-2000 [5, 6]. This trend represents a major increase in exposure to a possible risk factor for VTE.

It will be necessary to obtain some estimate of the degree of risk associated with immobility while sitting using a computer, to enable appropriate recommendations to be made regarding prophylaxis. With the

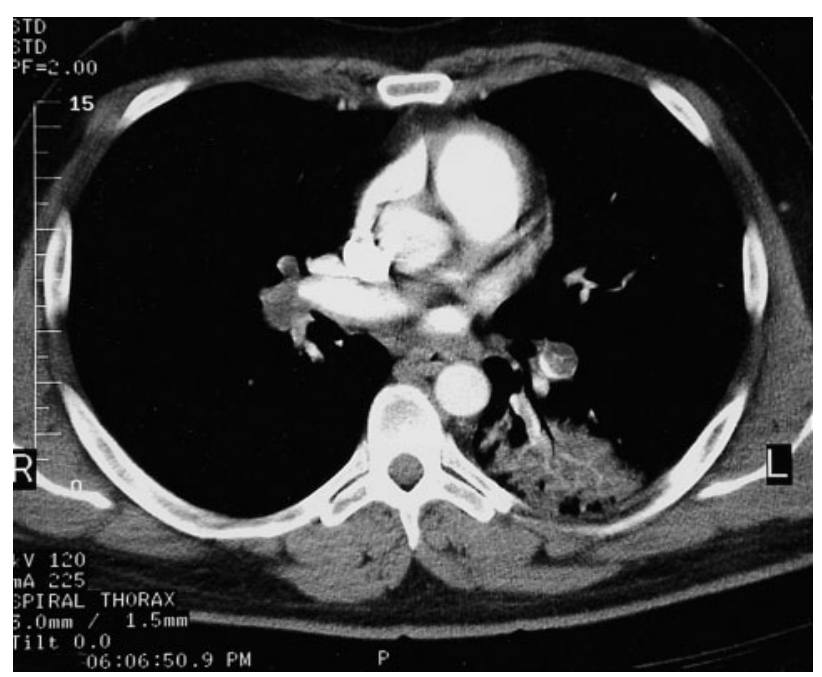

Fig. 3.- Helical computed tomography angiogram showing thrombus in both lower lobe pulmonary arteries with a wedge-shaped consolidation in the superior segment of the left lower lobe. 
current state of knowledge it would seem prudent to advise all individuals who commonly sit for prolonged periods at a computer to undertake frequent leg and foot exercises and take regular breaks for mobilisation away from the computer. In this way it may be possible to reduce the potential considerable burden of "eThrombosis".

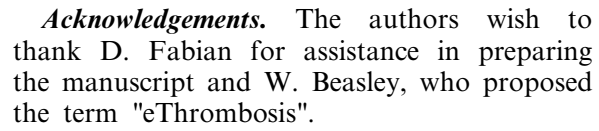

Acknowledgements. The authors wish to thank D. Fabian for assistance in preparing the manuscript and W. Beasley, who proposed the term "eThrombosis".

\section{References}

1. Simpson K. Shelter deaths from pulmonary embolism. Lancet 1940; i: 744.
2. Homans J. Thrombosis of the deep leg veins due to prolonged sitting. N Engl J Med 1954; 250: 148-149.

3. Scurr JH, Machin SJ, Bailey-King S, Mackie IJ, McDonald S, Coleridge Smith PD. Frequency and prevention of symptomless deep-vein thrombisis in long-haul flights: a randomised trial. Lancet 2001; 357: 1485-1489.

4. Belcaro G, Geroulakos G, Nicolaides AN, Myers KA, Winford M. Venous thromboembolism from air travel: the LONFLIT study. Angiology 2001; 52: 369-374.

5. Newburger EC. Home computers and internet use in the United States: August 2000. Current Population Report, US Census Bureau, US Dept of Commerce, September 2001; pp. 1-9.

6. Newburger EC. Computer use in the United States: October 1997. Current Population Report, US Census Bureau, US Dept of Commerce, September1999; pp. 1-11. 